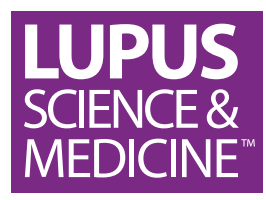

\title{
Impact of pregnancy in patients with systemic lupus erythematosus- associated pulmonary arterial hypertension: case series and literature review
}

\author{
Mucong Li (D , , Zhuang Tian, ${ }^{2}$ Junyan Qian, ${ }^{1}$ Can Huang, ${ }^{1}$ Jiuliang Zhao, ${ }^{1}$ \\ Qian Wang, ${ }^{1}$ Yijun Song, ${ }^{3}$ Xinping Tian, ${ }^{1}$ Mengtao Li, ${ }^{1}$ Juntao Liu, ${ }^{3}$ Xiaofeng Zeng ${ }^{1}$
}

To cite: Li M, Tian Z, Qian J, et al. Impact of pregnancy in patients with systemic lupus erythematosusassociated pulmonary arterial hypertension: case series and literature review. Lupus Science \& Medicine 2022;9:e000636. doi:10.1136/ lupus-2021-000636

- Additional supplemental material is published online only. To view, please visit the journal online (http://dx.doi.org/10. 1136/lupus-2021-000636).

$\mathrm{ML}$ and $\mathrm{ZT}$ contributed equally.

Received 6 December 2021 Accepted 17 February 2022

\section{Check for updates}

(C) Author(s) (or their employer(s)) 2022. Re-use permitted under CC BY-NC. No commercial re-use. See rights and permissions. Published by BMJ.

For numbered affiliations see end of article.

\section{Correspondence to} Dr Jiuliang Zhao; zjlpumc@ sina.com and Dr Yijun Song; 13681191769@163.com

\section{ABSTRACT}

Objective This study aimed to investigate the clinical characteristics and outcomes of pregnancy complicated by SLE-associated pulmonary arterial hypertension (SLE-PAH) in a case series and literature review.

Methods This single-centre retrospective study included 10 consecutive pregnancies complicated by SLE-PAH confirmed by right heart catheterisation (RHC) at Peking Union Medical College Hospital between 2009 and 2020. A literature search was conducted and 14 pregnancy cases complicated by SLE-PAH were reviewed.

Results At the time of 10 patients' initial visits, the average age was $30.00 \pm 5.72$ years and the median disease duration of SLE and PAH was 34.5 (range 1-164) months and 2 (1-51) months. Two patients carried planned pregnancy, seven patients developed PAH during pregnancy and one pregnancy was unplanned. Further, nine patients had low disease activity, with Systemic Lupus Erythematosus Disease Activity Index between 0 and 4 , and $30 \%, 30 \%$ and $40 \%$ of patients were of WHO functional class II, III and IV, respectively. All patients were evaluated by $\mathrm{RHC}$ and echocardiography. $\mathrm{N}$-terminal pro-brain natriuretic peptide (NT-proBNP) levels were elevated in $70 \%$ of patients, with a median level of $776(56-18023) \mathrm{pg} /$ $\mathrm{mL}$. The median time of completed pregnancies in all patients was 31 (15-38) weeks and six patients delivered live infants. SLE activity and PAH severity improved in $70 \%$ of patients within 6 months after delivery. One patient died on the 15th day after induction of labour. In the remaining patients, all achieved a lupus low disease activity state; according to the European Society of Cardiology/European Respiratory Society risk stratification, seven were categorised at a lower risk state compared with their risk stratification during pregnancy, and two remained at intermediate risk. Additionally, $80 \%$ of patients exhibited mild impairments with WHO functional class I or II. The median NT-proBNP level was 184 (32-4003) pg/mL within 6 months after delivery. In the reviewed literature, the average age of patients was $30.09 \pm 5.37$ years. The median time of completed pregnancies was 36 (28-40) weeks. More cases were planned and successful, and the survival rates of mothers and neonates were $85.71 \%$ and $92.86 \%$, respectively. Conclusions Successful pregnancy could be possible in women with SLE-PAH if SLE-PAH treatment goals are achieved under proper therapies, careful monitoring and thorough evaluations.

\section{Key messages}

What is already known about this subject?

- Pregnancy is a serious condition in women of childbearing age with SLE-associated pulmonary arterial hypertension (SLE-PAH).

- Several successful pregnancies have been reported in patients with SLE-PAH; however, there is a lack of publications and guidelines on decision-making and management of pregnancy in SLE-PAH.

What does this study add?

- This study included 10 consecutive pregnant patients with SLE-PAH confirmed by right heart catheterisation and reviewed 14 cases from previous studies.

- The overall survival rates of mothers and neonates were $87.5 \%$ and $79.17 \%$, respectively.

- Successful pregnancy may be possible in reproductive-age women with SLE-PAH when SLE$\mathrm{PAH}$ is well controlled and treatment goals are achieved through careful planning and appropriate PAH-specific therapies.

How might this impact on clinical practice or future developments?

- Pregnancy in this population is still a major challenge for both patients and physicians; however, a combination of proper therapy, monitoring and evaluation may contribute to lowering the risk of adverse events in pregnancy cases complicated by SLE-PAH.

\section{INTRODUCTION}

SLE is a multisystem autoimmune disease that mainly occurs in women of childbearing age. Advances in therapy and management over the past several decades have facilitated satisfaction of fertility needs of most women with SLE. ${ }^{1}$ Pulmonary arterial hypertension $(\mathrm{PAH})$ is a rare but severe complication of SLE, with incidence varying from $2.06 \%$ to $3.83 \%$ in affected patients. ${ }^{2-4}$ Due to rapid 
disease progression and lack of effective treatments, the prognosis for patients with SLE-PAH is worse than for those with SLE alone, with a 3-year survival rate of $45.0 \%-$ $89.4 \% .^{5-8}$

Pregnancy in patients with SLE-PAH is recognised as a serious and complicated scenario as it can result in negative consequences for both mothers and neonates, especially maternal death. ${ }^{9-12}$ Additionally, few publications and guidelines have focused on decision-making and management of pregnancy in women with SLE-PAH. Several recent case reports have shown that pregnancy is feasible in patients with SLE-PAH. ${ }^{13-20}$ These investigations suggested the possibility of successful pregnancy complicated by SLE-PAH and served as the foundation for future management and treatment guidelines.

This is the first study of pregnant women with SLEPAH confirmed by right heart catheterisation (RHC) and the first systematic review of all eligible pregnancy cases complicated by SLE-PAH reported in previous studies. Our study provides an overview of the clinical characteristics, management and outcomes of pregnant women with SLE-PAH.

\section{METHODS \\ Subjects}

This single-centre retrospective study was conducted at Peking Union Medical College Hospital. Consecutive pregnancy cases complicated by SLE-PAH were collected from May 2009 to September 2020. A search for inpatient and outpatient data in the hospital information system of Peking Union Medical College Hospital and the Chinese Lupus Treatment and Research Group registry was performed. All applicable medical records for patients were reviewed. Cases were included if (1) the patient fulfilled the Systemic Lupus International Collaborating Clinics (SLICC) 2012 classification criteria for SLE; (2) the patient had a diagnosis of PAH with mean pulmonary artery pressure $(\mathrm{mPAP}) \geq 25 \mathrm{~mm} \mathrm{Hg}$ confirmed by RHC; and (3) PAH was diagnosed before or during pregnancy. A completed pregnancy included pregnancy with induced labour or uninduced labour (including liveborn infants by vaginal or caesarean and stillbirth). Planned pregnancy was defined as planning of the pregnancy by the patient with awareness of potential risks in coordination with family members and physicians. Extracted patient demographics included age, disease duration, whether the pregnancy was planned and autoantibody levels. Obstetric characteristics were collected including pregnancy history, time of pregnancies completed, mode of delivery and anaesthesia, and maternal and neonatal outcomes. Clinical evaluation of SLE was based on the Systemic Lupus Erythematosus Disease Activity Index (SLEDAI), organ involvement, the American College of Rheumatology/SLICC Damage Index and Physician Global Assessment. Assessment of PAH was according to the European Society of Cardiology/European Respiratory Society (ECS/ERS) risk stratification, including related symptoms and their progression, WHO functional class, echocardiography results, and N-terminal pro-brain natriuretic peptide (NT-proBNP) levels at baseline and within 6 months after delivery. ${ }^{21-23}$

Literature review of pregnancy cases complicated by SLE-PAH We conducted a literature search in PubMed before 7 August 2021, with combined terms of PAH and pregnancy (online supplemental figure 1). Studies were eligible if (1) the patient was diagnosed with SLE using a validated standard diagnosis; (2) the patient had a diagnosis of PAH confirmed by either RHC or echocardiography (mPAP $\geq 25 \mathrm{~mm} \mathrm{Hg}$ ); (3) PAH was diagnosed before or during pregnancy; (4) the study was an original study published in English, including a case report, case series, case-control or retrospective cohort study; and (5) detailed medical information could be obtained. The exclusion criteria were as follows: (1) pulmonary hypertension was due to other causes, such as idiopathic PAH, heritable $\mathrm{PAH}$, and pulmonary hypertension secondary to cardiac and interstitial lung diseases; and (2) there is a lack of detailed clinical records of the patient, including WHO functional class or mPAP level, and maternal outcomes. Eleven studies were finally included in the literature review, seven of which were case reports and four were retrospective studies; relevant medical information was then extracted.

\section{Statistical methods}

Descriptive and continuous data are shown in the tables. Descriptive data were presented as percentages. Continuous data were expressed as mean \pm SD or median (range) if they do not conform to a normal distribution. Data were analysed using SPSS V.23.0 and Prism V.9 (GraphPad Software, La Jolla, California, USA).

\section{RESULTS}

\section{Baseline characteristics}

Ten pregnant women who were diagnosed with SLE-PAH between April 2012 and August 2019 were identified at our hospital. Patient baseline characteristics and disease evaluation results are shown in table 1 . The average age at the patients' first visits during pregnancy was 30.0 5 5.7 years. The median disease duration of SLE and PAH at baseline was 34.5 (range 1-164) months and 2 (1-51) months, respectively. Among these 10 patients, 2 planned their pregnancy with a full understanding of the risks and possible harm, 7 patients developed PAH during their pregnancy, and 1 pregnancy was unplanned (case 5). Nine cases were multigravida, and five primiparas were enrolled in this study. None of these women experienced previous pregnancy-related complications, such as preeclampsia or intrauterine growth restriction. Detailed pregnancy histories are reported in table 1.

All cases were positive for ANA, seven were positive for anti-Sjogren's syndrome antigen A (anti-SSA), two were positive for anti-Sjogren's syndrome antigen B (anti-SSB) and two were positive for anti-double strand DNA 


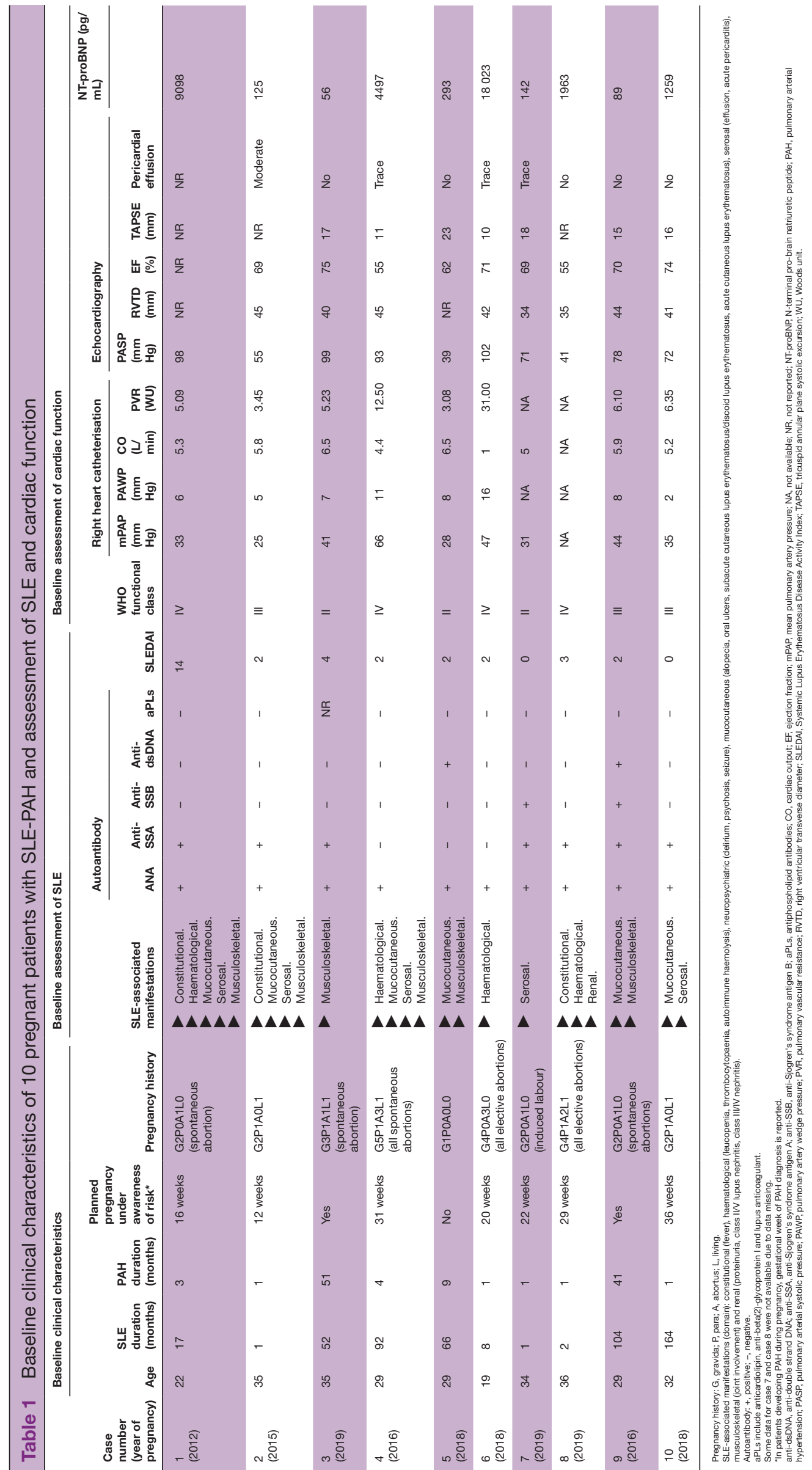


(anti-dsDNA). Nine patients with reported laboratory results were all negative for antiphospholipid antibodies, including anticardiolipin, anti-beta(2)-glycoprotein I and lupus anticoagulant. Nine patients had low disease activity, with SLEDAI between 0 and 4 . The SLEDAI score of case 1 was 14 , indicating moderately active SLE.

Right heart function was assessed using clinical features and laboratory data. The percentages of patients with WHO functional class I, II, III and IV were $0 \%, 30 \%$, $30 \%$ and $40 \%$, respectively. RHC is the gold standard for the diagnosis of PAH and was used to evaluate PAH at all of the patients' first visits. As listed in table 1, all patients had an elevated mPAP $(\geq 25 \mathrm{~mm} \mathrm{Hg})$ and pulmonary vascular resistance (PVR $\geq 3$ Woods unit, WU). The median mPAP, pulmonary artery wedge pressure, cardiac output and PVR were 35 (25-66) $\mathrm{mm} \mathrm{Hg}, 7.5$ (2-16) mm $\mathrm{Hg}, 5.3$ (1-6.5) L/min and 5.67 (3.08-31.00) WU, respectively. Echocardiography was used to evaluate PAH and monitor patients' cardiac function during pregnancy as it is a non-invasive measurement. The median pulmonary arterial systolic pressure (PASP) was 75 (39-102) mm Hg. The median tricuspid annular plane systolic excursion (TAPSE) was 16 (10-23) $\mathrm{mm}$, indicating impaired right ventricular function in most patients. However, dilation of right ventricle was not observed in any of the patients and no reduction in ejection fraction (EF) was found in nine patients with recorded EF. Only one patient (case 2) was confirmed to have a moderate pericardial effusion via echocardiography. NT-proBNP levels were elevated in $70 \%$ of patients, with a median of 776 (56-18 023) $\mathrm{pg} / \mathrm{mL}$ in all cases. Detailed baseline characteristics are presented in table 1 .

\section{Maternal and neonatal outcomes}

Nine of 10 patients were administered corticosteroid therapy during pregnancy. Immunosuppressive agents, PAH-targeted medications and supportive treatments were adjusted according to patients' manifestations and drug teratogenicity around pregnancy (online supplemental table 1).

Four out of 10 patients underwent induced labour. Among the other six pregnancies without induced labour (including both planned pregnancies, cases 3 and 9), five patients delivered their neonates via caesarean section and one delivered vaginally. The median time of pregnancies completed in all patients, patients with induced labour and patients without induced labour was 31 (15-38) weeks, 22 (15-25) weeks and 33 (31-38) weeks, respectively. Of the 10 patients, $40 \%$ were administered general anaesthesia and $60 \%$ were administered continuous epidural anaesthesia.

Table 2 shows that most patients in our study benefited from completed pregnancies regardless of its form. In general, SLE activity and PAH severity improved in $70 \%$ of patients and remained stable in 20\% of patients within 6 months after delivery. One patient (case 6) died of shock caused by deterioration of cardiac function and infection 15 days after induced labour. In the other patients,
SLEDAI remained $0-4$, no disease flared and no new organ was involved within 6 months after delivery, indicating a lupus low disease activity state. According to ECS/ ERS risk stratification, all alive patients were categorised at a lower risk state compared with their risk stratification during pregnancy, except for cases 3 and 5 who remained at intermediate risk. Regarding cardiac function evaluated using WHO functional class within 6 months after delivery, $80 \%$ of patients exhibited mild impairments (WHO functional class I or II). The median PASP of all surviving patients was 59 (23-83) $\mathrm{mm} \mathrm{Hg}$, indicating the improvement of PAH in this group. The median TAPSE was 15 (14-21) $\mathrm{mm}$, which was similar to the level at baseline. Pericardial effusion could not be detected after delivery in case 2. In all surviving patients, the median of NT-proBNP level decreased from 293 (56-9098) pg/ $\mathrm{mL}$ at baseline to $184(32-4003) \mathrm{pg} / \mathrm{mL}$ within 6 months after delivery. Decreases in NT-proBNP levels were especially remarkable in patients with NT-proBNP levels higher than 10-fold upper limit of normal (ULN, $125 \mathrm{pg}$ / $\mathrm{mL}$ ) at baseline. It was also observed that the levels of NT-proBNP were lower than threefold ULN in eight out of nine surviving patients (figure 1A). However, several results of echocardiography indicated deterioration of cardiac function within 6 months after delivery. Right ventricular dilation was not detected in most patients, except for case 4 , whose right ventricular transverse diameter was $50 \mathrm{~mm}$. It was notable that reduction in $\mathrm{EF}$ was found in two out of eight patients with recorded EF.

Despite prematurity and low birth weight in most of six neonates, the 5 min Apgar scores of all infants were in the normal range (7-10). Five of six infants were admitted to the neonatal intensive care unit for 4-30 days due to preterm birth and/or low birth weight. There was no neonatal mortality, and no severe diseases were reported in these children until the last follow-up in January 2022.

\section{Literature review}

A review of the literature included 14 pregnancy cases complicated by SLE-PAH in 11 studies from 2002 to 2021. ${ }^{13-18}{ }^{24-28}$ Most patients (except for the case in Zhou et $a l^{24}$ ) delivered via caesarean section $(76.92 \%)$; the others delivered vaginally (23.08\%). The low proportion of induced labour was the most distinct characteristic of the cases in the literature compared with cases at our hospital. However, these patients shared some similar clinical features with the patients at our hospital. The average age of patients from our literature review was $30.09 \pm 5.37$ years. The median time of their completed pregnancies was 36 (28-40) weeks, which was similar to the data for patients with uninduced labour at our hospital. Further, more pregnancies were planned in the 14 reviewed cases. Regarding obstetric outcomes, the survival rates of mothers and neonates were $85.71 \%$ and $92.86 \%$ respectively. Assessment of cardiac function at baseline and/or after delivery, including WHO functional class and levels of mPAP and NT-proBNP, was reported in some of the cases from the reviewed literature. WHO functional class 


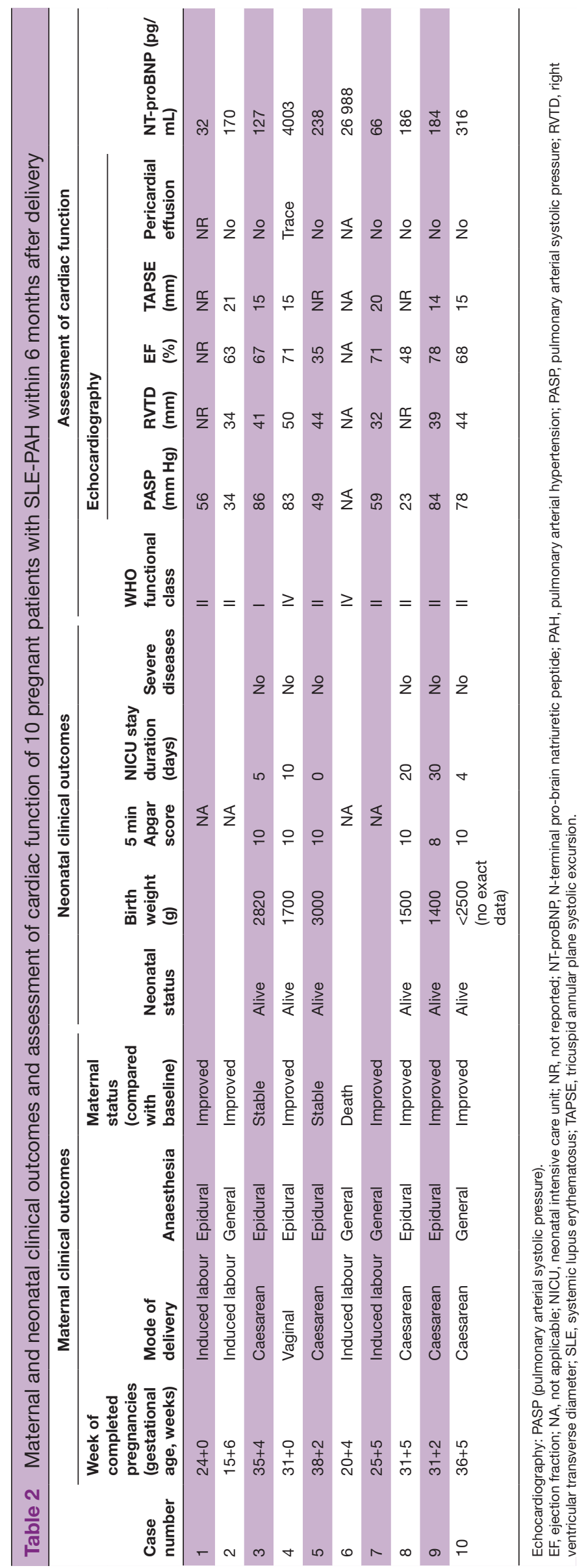

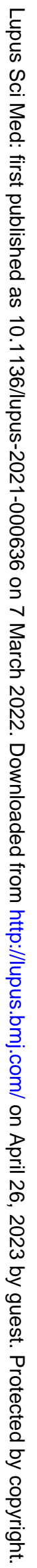




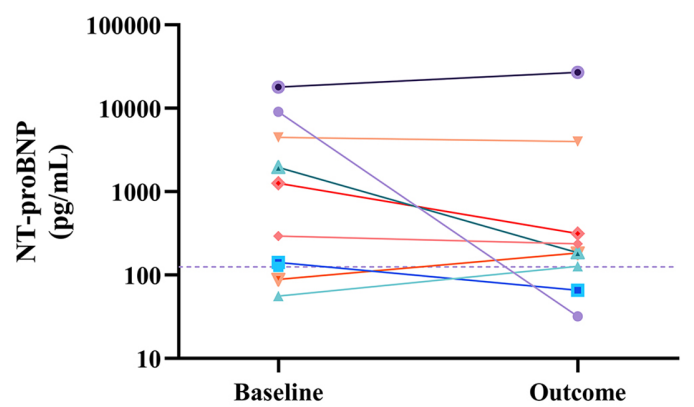

$$
\begin{aligned}
& \rightarrow 1 \#-6 \text { - } 6 \text { \# } \\
& -2 \#-\frac{-1}{-} 7 \# \\
& \text { - } 3 \#-1 \text { - } 8 \text { \# } \\
& \rightarrow 4 \#-7-9 \# \\
& \rightarrow 5 \#-10 \# \\
& \text { - Upper limit of normal }
\end{aligned}
$$

\section{A}

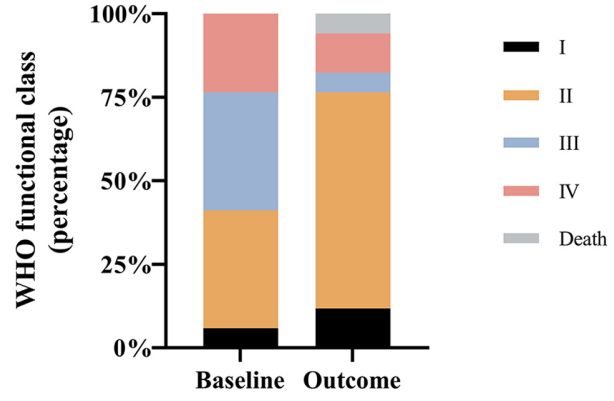

Figure 1 NT-proBNP and WHO functional class of pregnant patients with SLE-PAH at our hospital and previous studies at baseline and within 6 months after delivery. (A) NT-proBNP of 10 pregnant patients with SLE-PAH at our hospital at baseline and within 6 months after delivery. (B) WHO functional class of 17 pregnant patients with SLE-PAH at our hospital and previous studies at baseline and within 6 months after delivery. NT-proBNP, N-terminal pro-brain natriuretic peptide; PAH, pulmonary arterial hypertension.

at baseline and after delivery was available in seven cases in the literature and ten cases at our hospital. Figure 1B illustrates that in these 17 patients, the percentage of patients with WHO functional class I and II rose from $41.18 \%$ to $76.47 \%$. Further clinical characteristics, outcomes and assessment of cardiac function are displayed in table 3 .

\section{DISCUSSION}

This is the first retrospective study of consecutive pregnancy cases complicated by SLE-PAH confirmed by RHC. In our case series and literature review, we explored the possibility of pregnancy in patients with SLE-PAH by comprehensively analysing obstetric outcomes and critically evaluating primary disease and cardiac function.

The mortality of pregnant patients with $\mathrm{PAH}$ ranges from $12 \%$ to $56 \%,{ }^{29}$ which is much higher than that of healthy population. Previous evidence has suggested that connective tissue disease-associated PAH may be related to lower survival rates and worse prognosis compared with other types of PAH. ${ }^{31}$ A majority of pregnant women with other types of PAH had better cardiac function than our patients. ${ }^{30}$ Therefore, more attention and more intensive interventions are needed in PAH secondary to connective tissue diseases. Recently, outcomes of patients with connective tissue diseaseassociated PAH have significantly improved with advances in treatment-to-target therapies and novel target drugs. Some prior studies have even reported successful pregnancies in women with SLE-PAH, similar to the cases in our study. The improved survival can be attributed to proper management based on treatment-to-target therapy during the entire pregnancy. Our study demonstrated that maternal death did not occur in planned cases; however, it happened in two of ten unplanned cases, suggesting that planning prior to pregnancy may be associated with improved maternal survival. Moreover, in all successful delivered cases at our hospital, patients had SLEDAI scores ranging from 0 to 4 at baseline. Therefore, low disease activity may contribute to successful pregnancies in patients with SLE-PAH. Advanced and thorough evaluation by rheumatologists, PAH specialists, obstetricians, intensive care specialists and obstetric anaesthetists is suggested to minimise disease activity and organ damage and to optimise health-related quality-of-life in pregnant women with SLE-PAH. ${ }^{32}$ Taken together, a comprehensive management can considerably decrease the risks of pregnancy and improve prognoses in patients with SLE-PAH. It is recommended that shared decision on pregnancy should be made between informed patients, her family members and her physicians.

Most studies of pregnant women with pulmonary hypertension have only focused on congenital heart diseaseassociated pulmonary hypertension, which has exhibited good response to target therapy and tends to improve significantly through treatment. Unlike congenital heart disease-associated pulmonary hypertension, SLE-PAH is considered a potentially reversible condition because its severity is positively correlated with level of inflammation $^{33-36}$ and disease activity of SLE. ${ }^{37}$ Therefore, earlier and intensive immunosuppressive treatment for SLE is one of the most important components of a successful pregnancy outcome in a patient with SLE-PAH.

PAH-specific treatment is another important pillar of a treatment-to-target therapy in pregnant patients with SLE-PAH. Advances in target therapies have allowed successful pregnancies in patients with congenital heart disease-associated PAH. ${ }^{10} 3839$ Target therapies have also been used in pregnant patients with SLE-PAH in several case reports. ${ }^{132527}$ A combination therapy may further improve exercise tolerance, quality of life and patient survival. ${ }^{40-42}$ Phosphodiesterase-5 inhibitors and prostacyclin receptor agonists are relatively safe with the Food and Drug Administration (FDA) pregnancy category B (tadalafil, vardenafil, treprostinil) and $\mathrm{C}$ (iloprost), and can be used when necessary during pregnancy complicated by SLE-PAH. However, special attention must be paid to certain endothelin receptor antagonists and guanylate cyclase agonists (such as riociguat), which have teratogenic effects and must be avoided during pregnancy. ${ }^{43} 44$ Additionally, the comprehensive application of inotropic, diuretics, anti-infection, antiplatelets and anticoagulants, and oxygen therapies also has a positive effect on haemodynamic parameters and maternal outcomes. $^{45} 46$ 


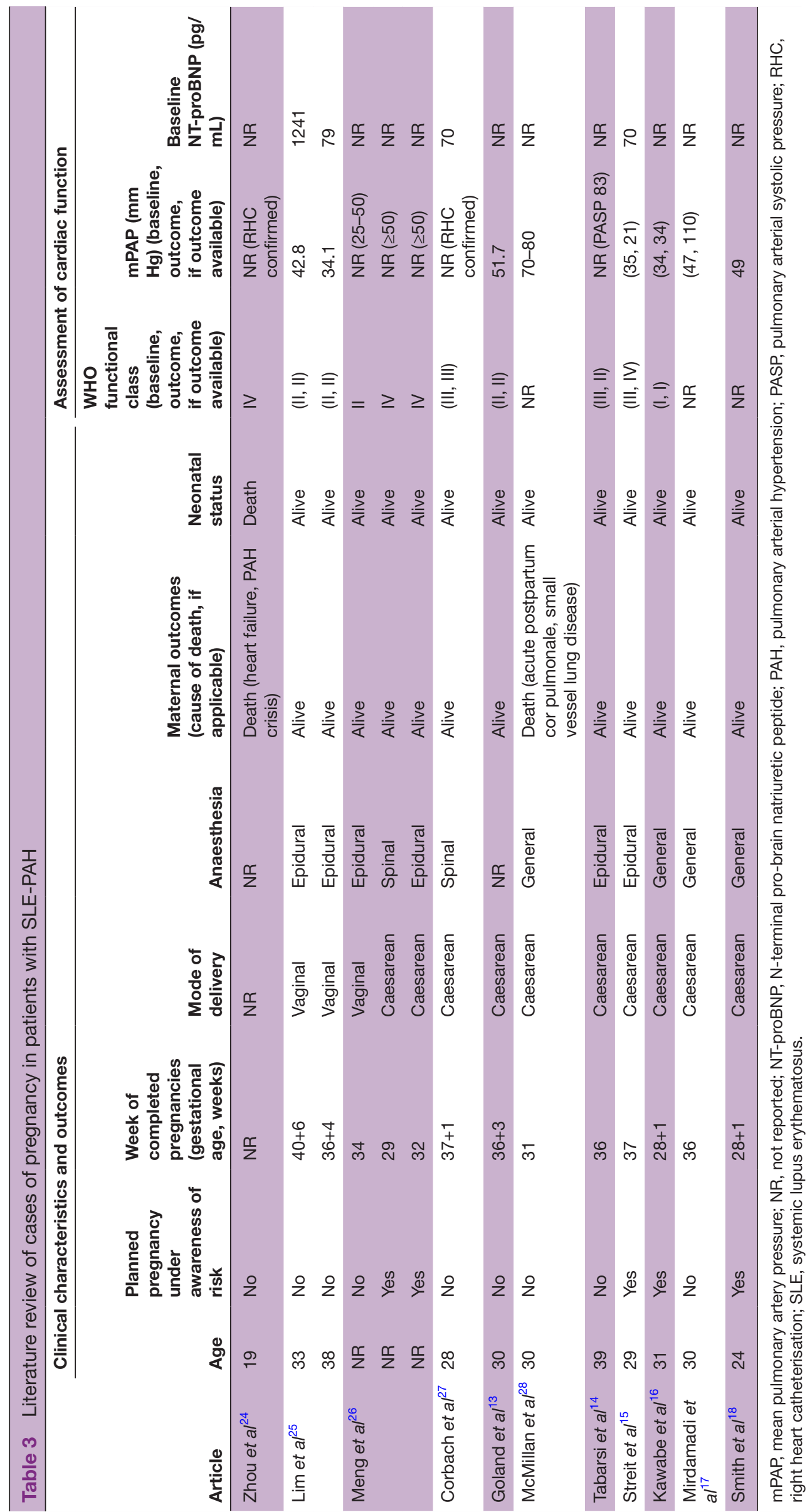

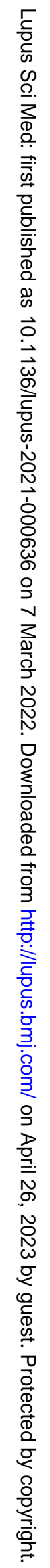


This case series is limited by its small size and broad time range of pregnancy cases complicated by SLE-PAH. Moreover, most of the reviewed literature set out to introduce successful managements of SLE-PAH pregnancy. Therefore, potential bias, such as an overestimation of the survival rate, in prior studies needs to be considered.

\section{CONCLUSION}

In conclusion, the results of this case series and literature review confirm that pregnancy is still a significant challenge for both patients and physicians; however, through careful planning and appropriate PAH-specific therapies, a successful pregnancy could be possible in women of reproductive age with SLE-PAH, especially when SLE-PAH is controlled quite well and treatment goals are achieved. Collaboration between patients, family members and physicians contributed to achieving a successful pregnancy outcome with awareness of potential risks. Therefore, a combination of proper therapy, monitoring and evaluation may contribute to lowering the risk of adverse events in pregnancy cases complicated by SLE-PAH. More attention should be given to establishing consensus on the management of SLE-PAH-associated pregnancies in future studies.

\section{Author affiliations}

${ }^{1}$ Department of Rheumatology, Peking Union Medical College Hospital (PUMCH), Peking Union Medical College and Chinese Academy of Medical Sciences, National Clinical Research Center for Dermatologic and Immunologic Diseases (NCRC-DID), Key Laboratory of Rheumatology and Clinical Immunology, Ministry of Education, Chinese Rheumatism Data Center (CRDC), Chinese SLE Treatment and Research Group (CSTAR), State Key Laboratory of Complex Severe and Rare Diseases, Peking Union Medical College Hospital, Chinese Academy of Medical Science and Peking Union Medical College, Beijing, China

${ }^{2}$ Department of Cardiology, Peking Union Medical College Hospital, Peking Union Medical College and Chinese Academy of Medical Sciences, Beijing, China ${ }^{3}$ Department of Obstetrics and Gynecology, Peking Union Medical College Hospital, Peking Union Medical College and Chinese Academy of Medical Sciences, Beijing, China

Contributors JZ, YS, ML, JL and XZ conceived and designed this study. ML, JQ, $\mathrm{CH}, \mathrm{QW}, \mathrm{ZT}$ and $\mathrm{XT}$ enrolled the patients, collected and analysed the data, and wrote the manuscript. Guarantor: JZ. All authors have read and approved this final manuscript.

Funding This study was supported by the Chinese National Key Technology R\&D Program, Ministry of Science and Technology (2021YFC2501305, 2021YFC2501306); Beijing Municipal Science and Technology Commission (No: Z201100005520022, 23, 25-27); Fundamental Research Funds for the Central Universities (2019XK320042); and Youth Programme of the National Natural Science Foundation of China (81900054).

Competing interests None declared.

Patient consent for publication Not required.

Ethics approval This study involves human participants but was not approved and does not contain personal and medical information about an identifiable individual. All participants gave informed consent to participate in the study before taking part. Provenance and peer review Not commissioned; externally peer reviewed. Data availability statement All data relevant to the study are included in the article or uploaded as supplementary information.

Supplemental material This content has been supplied by the author(s). It has not been vetted by BMJ Publishing Group Limited (BMJ) and may not have been peer-reviewed. Any opinions or recommendations discussed are solely those of the author(s) and are not endorsed by BMJ. BMJ disclaims all liability and responsibility arising from any reliance placed on the content. Where the content includes any translated material, BMJ does not warrant the accuracy and reliability of the translations (including but not limited to local regulations, clinical guidelines, terminology, drug names and drug dosages), and is not responsible for any error and/or omissions arising from translation and adaptation or otherwise.

Open access This is an open access article distributed in accordance with the Creative Commons Attribution Non Commercial (CC BY-NC 4.0) license, which permits others to distribute, remix, adapt, build upon this work non-commercially, and license their derivative works on different terms, provided the original work is properly cited, appropriate credit is given, any changes made indicated, and the use is non-commercial. See: http://creativecommons.org/licenses/by-nc/4.0/.

ORCID iD

Mucong Li http://orcid.org/0000-0003-0540-9078

\section{REFERENCES}

1 Andreoli L, Bertsias GK, Agmon-Levin N, et al. EULAR recommendations for women's health and the management of family planning, assisted reproduction, pregnancy and menopause in patients with systemic lupus erythematosus and/or antiphospholipid syndrome. Ann Rheum Dis 2017;76:476-85.

2 Li M, Wang Q, Zhao J, et al. Chinese SLE treatment and research Group (CSTAR) registry: II. prevalence and risk factors of pulmonary arterial hypertension in Chinese patients with systemic lupus erythematosus. Lupus 2014;23:1085-91.

3 Lin C-Y, Ko C-H, Hsu C-Y, et al. Epidemiology and mortality of connective tissue disease-associated pulmonary arterial hypertension: a national cohort study in Taiwan. Semin Arthritis Rheum 2020;50:957-62.

4 Yang X, Mardekian J, Sanders KN, et al. Prevalence of pulmonary arterial hypertension in patients with connective tissue diseases: a systematic review of the literature. Clin Rheumatol 2013;32:1519-31.

5 Hachulla E, Jais X, Cinquetti G, et al. Pulmonary arterial hypertension associated with systemic lupus erythematosus: results from the French pulmonary hypertension registry. Chest 2018;153:143-51.

6 Chung S-M, Lee C-K, Lee EY, et al. Clinical aspects of pulmonary hypertension in patients with systemic lupus erythematosus and in patients with idiopathic pulmonary arterial hypertension. Clin Rheumatol 2006;25:866-72.

7 Hao Y-J, Jiang X, Zhou W, et al. Connective tissue diseaseassociated pulmonary arterial hypertension in Chinese patients. Eur Respir J 2014:44:963-72.

8 Zhao J, Wang Q, Liu Y, et al. Clinical characteristics and survival of pulmonary arterial hypertension associated with three major connective tissue diseases: a cohort study in China. Int J Cardiol 2017;236:432-437.

9 Duarte AG, Thomas S, Safdar Z, et al. Management of pulmonary arterial hypertension during pregnancy: a retrospective, multicenter experience. Chest 2013;143:1330-6.

10 Jha N, Jha AK, Mishra SK, et al. Pulmonary hypertension and pregnancy outcomes: systematic review and meta-analysis. Eur $\mathrm{J}$ Obstet Gynecol Reprod Biol 2020;253:108-16.

11 Bonnin M, Mercier FJ, Sitbon O, et al. Severe pulmonary hypertension during pregnancy: mode of delivery and anesthetic management of 15 consecutive cases. Anesthesiology 2005;102:1133-7.

12 Luo J, Shi H, Xu L, et al. Pregnancy outcomes in patients with pulmonary arterial hypertension: a retrospective study. Medicine 2020;99:e20285.

13 Goland S, Tsai F, Habib M, et al. Favorable outcome of pregnancy with an elective use of epoprostenol and sildenafil in women with severe pulmonary hypertension. Cardiology 2010;115:205-8.

14 Tabarsi N, Levy R, Rychel V, et al. Pregnancy among women with pulmonary arterial hypertension: a changing landscape? Int $J$ Cardiol 2014;177:490-1.

15 Streit M, Speich R, Fischler M, et al. Successful pregnancy in pulmonary arterial hypertension associated with systemic lupus erythematosus: a case report. J Med Case Rep 2009;3:7255.

16 Kawabe A, Nakano K, Aiko Y, et al. Successful management of pregnancy in a patient with systemic lupus erythematosusassociated pulmonary arterial hypertension. Intern Med 2018;57:1655-9.

17 Mirdamadi A, Gharavi H, Behjati M. Role of Meticulous observation: successful pregnancy in a 30 -year-old woman with severe pulmonary hypertension. Tanaffos 2016;15:187-90.

18 Smith JS, Mueller J, Daniels CJ. Pulmonary arterial hypertension in the setting of pregnancy: a case series and standard treatment approach. Lung 2012;190:155-60. 
19 Sun X, Feng J, Shi J. Pregnancy and pulmonary hypertension: an exploratory analysis of risk factors and outcomes. Medicine 2018;97:e13035.

20 Edens $\mathrm{C}$, Rodrigues BC, Lacerda MI, et al. Challenging cases in rheumatic pregnancies. Rheumatology 2018;57:v18-v25.

21 Kylhammar D, Kjellström B, Hjalmarsson C, et al. A comprehensive risk stratification at early follow-up determines prognosis in pulmonary arterial hypertension. Eur Heart J 2018;39:4175-81.

22 Galiè N, Channick RN, Frantz RP, et al. Risk stratification and medical therapy of pulmonary arterial hypertension. Eur Respir $J$ 2019;53:1801889.

23 Hoeper MM, Kramer T, Pan Z, et al. Mortality in pulmonary arterial hypertension: prediction by the 2015 European pulmonary hypertension guidelines risk stratification model. Eur Respir $J$ 2017;50. doi:10.1183/13993003.00740-2017. [Epub ahead of print: 0308 2017].

24 Zhou Q, Peng P, Liu X, et al. Evaluation of maternal and fetal outcomes in pregnancy complicated with pulmonary arterial hypertension. Ann Palliat Med 2021;10:1404-1410.

25 Lim K, Chang SA, Oh SY, S-y O, et al. Pulmonary arterial hypertension and pregnancy: single center experience in current era of targeted therapy. Korean Circ J 2019;49:545-54.

26 Meng M-L, Landau R, Viktorsdottir O, et al. Pulmonary hypertension in pregnancy: a report of 49 cases at four tertiary North American sites. Obstet Gynecol 2017;129:511-20.

27 Corbach N, Berlier C, Lichtblau M, et al. Favorable pregnancy outcomes in women with well-controlled pulmonary arterial hypertension. Front Med 2021;8:689764.

28 McMillan E, Martin WL, Waugh J, et al. Management of pregnancy in women with pulmonary hypertension secondary to SLE and antiphospholipid syndrome. Lupus 2002;11:392-8.

29 Weiss BM, Zemp L, Seifert B, et al. Outcome of pulmonary vascular disease in pregnancy: a systematic overview from 1978 through 1996. J Am Coll Cardiol 1998;31:1650-7.

30 Low T-T, Guron N, Ducas R, et al. Pulmonary arterial hypertension in pregnancy-a systematic review of outcomes in the modern era. Pulm Circ 2021;11:20458940211013671.

31 Thakkar V, Lau EMT. Connective tissue disease-related pulmonary arterial hypertension. Best Pract Res Clin Rheumatol 2016;30:22-38.

32 Regitz-Zagrosek V, Roos-Hesselink JW, Bauersachs J, et al. 2018 ESC guidelines for the management of cardiovascular diseases during pregnancy. Eur Heart $J$ 2018;39:3165-241.

33 Hassoun PM, Mouthon L, Barberà JA, et al. Inflammation, growth factors, and pulmonary vascular remodeling. J Am Coll Cardiol 2009;54:S10-19.
34 Price LC, Wort SJ, Perros F, et al. Inflammation in pulmonary arterial hypertension. Chest 2012;141:210-21.

35 Frid MG, Thurman JM, Hansen KC, et al. Inflammation, immunity, and vascular remodeling in pulmonary hypertension; evidence for complement involvement? Glob Cardiol Sci Pract 2020;2020:e202001

36 Huang C, Zhang S, Tian Z, et al. Could pulmonary arterial hypertension be an active index of systemic lupus erythematosus? A successful case of SLE-PAH cured by methylprednisolone pulse therapy. Lupus 2014;23:1533-6.

37 Traynor AE, Corbridge TC, Eagan AE, et al. Prevalence and reversibility of pulmonary dysfunction in refractory systemic lupus: improvement correlates with disease remission following hematopoietic stem cell transplantation. Chest 2005;127:1680-9.

38 Ekici $\mathrm{H}$, Imamoglu M, Okmen F, et al. Pulmonary hypertension in pregnancy: experience from 45 cases at a tertiary care center. $J$ Matern Fetal Neonatal Med 2020:1-6.

39 Zhang J, Lu J, Zhou X, et al. Perioperative management of pregnant women with idiopathic pulmonary arterial hypertension: an observational case series study from China. J Cardiothorac Vasc Anesth 2018;32:2547-59.

40 Mathai SC, Girgis RE, Fisher MR, et al. Addition of sildenafil to bosentan monotherapy in pulmonary arterial hypertension. Eur Respir J 2007;29:469-75.

41 McLaughlin VV, Benza RL, Rubin LJ, et al. Addition of inhaled treprostinil to oral therapy for pulmonary arterial hypertension: a randomized controlled clinical trial. J Am Coll Cardiol 2010;55:1915-22.

42 Ghofrani HA, Wiedemann R, Rose F, et al. Combination therapy with oral sildenafil and inhaled iloprost for severe pulmonary hypertension. Ann Intern Med 2002;136:515-22.

43 Makowski CT, Rissmiller RW, Bullington WM. Riociguat: a novel new drug for treatment of pulmonary hypertension. Pharmacotherapy 2015;35:502-19.

44 Hitzerd E, Neuman RI, Broekhuizen M, et al. Transfer and vascular effect of endothelin receptor antagonists in the human placenta. Hypertension 2020;75:877-84.

45 Yang $M$, Wang J, Zhang $X$, et al. Incidence and long-term outcomes of pregnant women complicated with pulmonary arterial hypertension during different pregnancies: a prospective cohort study from China. Int J Cardiol 2021;326:178-183.

46 Sliwa K, van Hagen IM, Budts W, et al. Pulmonary hypertension and pregnancy outcomes: data from the registry of pregnancy and cardiac disease (ROPAC) of the European Society of cardiology. Eur $J$ Heart Fail 2016;18:1119-28. 